\title{
The Clustering of Axonal Sodium Channels during Development of the Peripheral Nervous System
}

\author{
Ian Vabnick, ${ }^{1}$ Sanja D. Novaković, ${ }^{1}$ S. Rock Levinson, ${ }^{2}$ Melitta Schachner, ${ }^{3}$ and Peter Shrager ${ }^{1}$ \\ ${ }^{1}$ Department of Physiology, University of Rochester, Rochester, New York 14642, 2Department of Physiology, University \\ of Colorado, Denver, Colorado 80262, and ${ }^{3}$ Department of Neurobiology, Eidgenössische Technische Hochschule, \\ Zürich CH 8093, Switzerland
}

\begin{abstract}
The distribution of $\mathrm{Na}^{+}$channels in rat peripheral nerve was measured during development by using immunofluorescence. Small segments of sciatic nerve from postnatal day 0-13 (P0$\mathrm{P} 13)$ pups were labeled with an antibody raised against a well conserved region of the vertebrate $\mathrm{Na}^{+}$channel. At day P0 axons contained almost no $\mathrm{Na}^{+}$channel aggregates. The number of clusters increased dramatically throughout the first week. In almost all cases $\mathrm{Na}^{+}$channels clustered in the vicinity of Schwann cell processes. At least four classes of aggregates were noted. Clusters formed singly at Schwann cell edges, in pairs or in broad regions between neighboring Schwann cells, and in more focal zones at presumptive nodes. Almost all $\mathrm{Na}^{+}$ channel aggregates had reached the latter stage by the end of
\end{abstract}

the first week. Histograms plotting the frequency of occurrence of each cluster type suggested a sequence of events in node formation involving the initiation of channel aggregation by Schwann cell processes. The requirement for Schwann cells during sodium channel clustering was tested by blocking proliferation of these cells with the antimitotic agent mitomycin C. $\mathrm{Na}^{+}$channel clustering was sharply reduced, whereas node formation was normal at a distal site along the same nerve. Immunocytochemical detection of myelin-associated glycoprotein (MAG) indicated that Schwann cells must begin to ensheathe axons before inducing $\mathrm{Na}^{+}$channel clustering.

Key words: myelin; sodium channel; axon; Schwann cell; glia; development
During development of the peripheral nervous system, myelination and node of Ranvier formation take place during early postnatal stages. Efficient and rapid axonal transmission via saltatory conduction is critically dependent on these processes as well as on the function of voltage-dependent ion channels. In adult axons the distribution of $\mathrm{Na}^{+}$channels is highly heterogeneous. The channels are present at high density at nodes and at much lower levels in paranodal and internodal zones (Shrager, 1989). What determines the location of nodes along a fiber and which mechanism is responsible for $\mathrm{Na}^{+}$channel clustering at these sites? Early studies focused on morphological specializations that were found at mature nodes but were not otherwise specific for $\mathrm{Na}^{+}$channels. This initial research provided evidence for early aggregation of intramembranous particles, generally associated with glial contact, and for a localized, unique cytoskeletal organization (Waxman and Foster, 1980; Wiley-Livingston and Ellisman, 1980; Tao-Cheng and Rosenbluth, 1983). More recently, evidence has been presented from in vitro studies that suggests that Schwann cells play an important role in channel aggregation (Joe and Angelides, 1992). Neuron-glial communication can be mediated via recognition-adhesion molecules at the cell surface. For example, several studies show that adhesion molecules of the immunoglobulin superfamily are important for

\footnotetext{
Received Feb. 5, 1996; revised May 16, 1996; accepted May 23, 1996.

This work was supported by Grants NS15879 and NS17965 from National Institutes of Health, Grant RG-2687 and postdoctoral fellowship FA-1169 from the National Multiple Sclerosis Society, and the Lucille P. Markey Charitable Trust Award to the University of Rochester. We thank Ellen Brunschweiger for expert technical assistance.

Correspondence should be addressed to Dr. Peter Shrager, Department of Physiology, Box 642, University of Rochester Medical Center, 601 Elmwood Avenue, Rochester, NY 14642.

Copyright (C) 1996 Society for Neuroscience $0270-6474 / 96 / 164914-09 \$ 05.00 / 0$
}

Schwann cell ensheathment of axons (Seilheimer et al., 1989; Fruttiger et al., 1995). Furthermore, the expression of various surface glycoproteins by glia and axons is dependent on developmental state (Martini and Schachner, 1986; Rieger et al., 1986; Nolte et al., 1989; Shatz, 1990).

In this paper we study the process of channel clustering and node formation in developing rats in vivo. We label $\mathrm{Na}^{+}$channels by immunofluorescence and examine dissociated axons over distances of sufficient length for quantitative analysis. Several stages in $\mathrm{Na}^{+}$channel cluster formation are identified and measured. By following the distribution of these intermediate forms over the first postnatal week, we suggest a possible progression of events for node of Ranvier development.

An abstract describing parts of this work has appeared previously (Vabnick et al., 1995).

\section{MATERIALS AND METHODS}

Primary antibodies. For $\mathrm{Na}^{+}$channel immunolocalization, rabbit polyclonal antibodies were raised against a highly conserved 18 -amino-acid peptide (TEEQKKYYNAMKKLGSKK) located between domains III and IV in the $\alpha$-subunit of the vertebrate $\mathrm{Na}^{+}$channel. The peptide was synthesized in the institutional facility at the University of Colorado Medical School and was conjugated to maleimide-activated keyhole limpet hemocyanin (KLH). Rabbits were immunized at 4 week intervals. Antibodies were purified by affinity chromatography (ImmunoPure $\mathrm{Ag} / \mathrm{Ab}$ Kit \#2, Pierce, Rockford, IL) with the immobilized peptide described above. Anti-myelin-associated glycoprotein (anti-MAG) monoclonal antibodies were prepared by immunization with affinity-purified glycoproteins carrying the L2 epitope from 1-2-d-old chicken brains. An IgG monoclonal antibody to MAG was obtained by the fusion of a mouse myeloma clone P3X63Ag8.653 with spleen cells from immunized mice. Details are available in Poltorak et al. (1987).

Immunofluorescence. Lewis rats from postnatal days 0 to 13 (P0-P13) were killed, and sciatic nerves were dissected, desheathed, and dissociated into individual fibers with collagenase, $3 \mathrm{mg} / \mathrm{ml}$, for $15-20 \mathrm{~min}$ at room temperature (RT). Segments of axons $(2-3 \mathrm{~mm})$ were held in place 
on coverslips with small, isolated spots of Cell-Tak (Collaborative Research, Bedford, MA). The tissue was fixed in $4 \%$ paraformaldehyde in $0.1 \mathrm{M}$ phosphate buffer (PB), pH 7.2, for $30 \mathrm{~min}$ and washed in $0.05 \mathrm{M} \mathrm{PB}$ ( $3 \times$ for $5 \mathrm{~min})$. Alternatively, in some cases nerves were fixed before desheathing. Then the preparation was permeabilized for $2 \mathrm{hr}$ in $0.1 \mathrm{M}$ $\mathrm{PB}, \mathrm{pH} 7.4$, containing $10 \%$ goat serum and $0.3 \%$ Triton X-100 (PBTGS), and exposed to the $\mathrm{Na}^{+}$channel antibody (1:50 in PBTGS) for $15 \mathrm{hr}$ at RT. Unless otherwise noted, all succeeding washes $(3 \times$ for $5 \mathrm{~min})$ and antibody dilutions were in PBTGS. Coverslips were washed and incu-

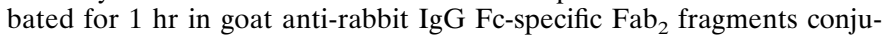
gated with biotin (1:200, Accurate Chemicals, Westbury, NY). The samples were washed and exposed to Extravidin-FITC (1:100, Sigma, St. Louis, MO). In control experiments, primary $\mathrm{Na}^{+}$channel antibodies were incubated overnight with a $50 \mathrm{M}$ excess of the peptide antigen at $4^{\circ} \mathrm{C}$ (unabsorbed primary antibody likewise was kept at $4^{\circ} \mathrm{C}$ ).

For double labeling, coverslips then were washed and incubated in anti-S100 (Sigma) or anti-MAG antibodies at 1:500 or 1:300 dilutions, respectively. They were washed and treated with goat anti-mouse antibody conjugated with TRITC (Sigma), diluted 1:200. Samples were washed successively in PBTGS, 0.1 M PB, and $0.05 \mathrm{M} \mathrm{PB}, \mathrm{pH} 7.4$. Then the preparation was air-dried and mounted on slides for observation on a Nikon Microphot fluorescence microscope. [When figure panels are lettered with and without a prime (e.g., $A, A^{\prime}$ ), they represent double labeling.] Images were collected with a SIT 68 camera (Dage-MTI, Michigan City, IN) connected to a DSP 2000 image processor (DageMTI) and were fed to a DT3851 series frame processor (Data Translation). A portion of the data was also collected by $35 \mathrm{~mm}$ photography with a Nikon N6000 camera. A focal region of immunofluorescence was considered to represent a cluster (aggregate) of $\mathrm{Na}^{+}$channels if (1) it was brightest at the edges of the fiber, consistent with surface labeling of a cylinder, and (2) it clearly stood out from background-nonspecific label. Spatial coordinates were measured by a pair of digital linear gauges with an accuracy of $\pm 1 \mu \mathrm{m}$ (EG-255, Ono Sokki Technology) mounted on the microscope stage. Gauge outputs were transferred to a laboratory computer, and at least two sections of nerve from each animal were analyzed.

Mitomycin injection. Day P0 rat pups were anesthetized by the procedure of Park et al., (1992). The dam was conditioned 1 week before birth by placing in the cage cotton batting containing saline, alcohol, and anesthetic and also a drop of Vetbond on a piece of surgical glove. The anesthetic Innovar-Vet (Janssen Pharmaceuticals, Ontario, Canada) was diluted with sterile Locke's 1:10. Pups were placed on a heating pad maintained at $38^{\circ} \mathrm{C}$. $0.02 \mathrm{ml}$ diluted Innovar-Vet was injected subcutaneously at the base of the tail. The pup was positioned on its side and, at the loss of the pedal withdrawal reflex, $100 \%$ oxygen flow was administered and continued for the remainder of the surgery. The sciatic nerve was exposed and was slipped over a glass rod to make it accessible for the injection. Mitomycin C, $400 \mathrm{mg} / \mathrm{ml}$, was dissolved in sterile Locke's, and $0.5 \mu \mathrm{l}$ was injected into the sciatic nerve via a glass micropipette broken to a tip diameter of $20-30 \mu \mathrm{m}$. The insoluble dye carmine red was included in the mitomycin solution to allow localization of the injection site. The wound was sealed with Vetbond, and the animal was revived with a subcutaneous injection of $0.02 \mathrm{ml}$ Naloxone $\mathrm{HCl}$ (Astra Pharmaceutical Products) at the base of its tail. As a control, littermates were injected with Locke's plus carmine red. The nerves were dissected 6 or $7 \mathrm{~d}$ after surgery for immunocytochemistry. The Locke's solution contained (in $\mathrm{mm}$ ): $\mathrm{NaCl} 154, \mathrm{KCl} 5.6, \mathrm{CaCl}_{2}$ 2, and HEPES 10, $\mathrm{pH}$ 7.4.

\section{RESULTS}

\section{Sodium channel aggregation during the first postnatal week}

Indirect immunofluorescence was used to characterize $\mathrm{Na}^{+}$channel aggregation over the first postnatal week. On day 0 (P0) most axons have adherent Schwann cells, many of which are seen with extended processes. However, very few fibers are found with regions labeled by the $\mathrm{Na}^{+}$channel antibody. Figure $1 A$ illustrates an axon and associated Schwann cell tested with the $\mathrm{Na}^{+}$ channel antibody. Only a very weak, diffuse label is noted, shown below to be nonspecific. There are no aggregates present. To see the extent of the glial processes, the preparation was also labeled for the Schwann cell-specific cytoplasmic protein S100 (Fig. 1 $A^{\prime}$ ). The processes seem to extend symmetrically along the axon. One day later $\mathrm{Na}^{+}$channel clusters were detected on axons. Figure $1 B$ shows small axonal sodium channel aggregates (large arrowheads) closely associated with the edges of an adherent Schwann cell. The Schwann cell was labeled with an antibody against MAG in Figure $1 B^{\prime}$. MAG and S100 were used in this experiment primarily as a means of visualizing the extent of glial processes. Below, we use MAG expression as a measure of the developmental state of Schwann cells. At days P0-P1 Schwann cells often were relatively isolated along axons, and the gap between neighboring processes was up to a few hundred micrometers in length. $\mathrm{Na}^{+}$channel clusters associated with these glial structures are called "single process" sites. Note additionally the small region of the Schwann cell body with the $\mathrm{Na}^{+}$channel label (Fig. 1B, small arrowhead). This was seen only occasionally. At day $\mathrm{P} 1$, of $99 \mathrm{MAG}^{+}$bipolar Schwann cell bodies examined, 10 had at least low level $\mathrm{Na}^{+}$ channel immunoreactivity with a similar pattern, and two had the relatively intense label seen in this figure. Schwann cell $\mathrm{Na}^{+}$ channel label was virtually absent by day $\mathrm{P} 2$. There is evidence for the presence of $\mathrm{Na}^{+}$channels in glia, but agreement with respect to myelinating Schwann cells is lacking (Chiu et al., 1984; Howe and Ritchie, 1990; Ritchie et al., 1990; Sontheimer et al., 1992; Chiu, 1993).

By day P3 the gap between adjacent Schwann cell processes was reduced to 3-10 $\mu \mathrm{m}$. At the wider sites $(>5 \mu \mathrm{m})$ two different classes of $\mathrm{Na}^{+}$channel aggregation were seen. Figure $1 C$ illustrates the pattern observed with the highest frequency-a single, broad $\mathrm{Na}^{+}$channel cluster. MAG labeling (Fig. $1 C^{\prime}$ ) shows that this aggregate was bordered at each edge by a Schwann cell process. This category of sites is called "broad clusters." $\mathrm{Na}^{+}$ channel label at other wide gaps was not uniform but, rather, had edges more intense than the center. This is seen in Figure $1 D$, which shows a fiber at day $\mathrm{P} 4$. This is reminiscent of the possible fusion of two channel aggregates seen during remyelination (Dugandzija-Novakovic et al., 1995) and is denoted "binary clusters." Again, the neighboring glial processes were MAG-positive (Fig. $1 D^{\prime}$ ). By the end of the first postnatal week, almost all sites of high $\mathrm{Na}^{+}$channel density had nodal characteristics. They were highly focal, as in Figure $1 E$, and were bordered by MAG-positive Schwann cell processes (Fig. $1 E^{\prime}$ ) that had increased caliber as compared with earlier stages (Fig. $1 C^{\prime}$ ). This class was called "presumptive nodes" and included all such clusters $<5 \mu \mathrm{m}$ in length.

Control experiments were performed to determine the specificity of the $\mathrm{Na}^{+}$channel antiserum. The primary antibody was preabsorbed with the peptide antigen before labeling the nerve. Figure 2 compares sites from day P3 that were labeled with normal (not preabsorbed) or blocked antiserum. Sodium channel labeling with normal serum was confined to axonal zones between MAG-positive Schwann cells (Fig. $2 A, A^{\prime}$ ). In contrast, only very weak, diffuse immunofluorescence was observed at such sites after exposure to preabsorbed antibody (Fig. $2 B, B^{\prime}$ ). This test was performed multiple times at several stages from days P1 to P5 with identical results. We therefore consider this residual labeling to be nonspecific, and it is not discussed further.

We have measured quantitatively the frequency of occurrence of the four classes of $\mathrm{Na}^{+}$channel clusters defined above. This was necessary because at each postnatal day there is a spectrum of axons at varying stages of node formation and myelination. Figure 3 gives histograms tabulating the number of clusters per unit length as a function of the postnatal day. Results for several segments of fibers were summed in each experiment. The total measured axonal length ranged between 15 and $37 \mathrm{~mm}$. Measurements were limited to regions spread sufficiently so as to be clearly 

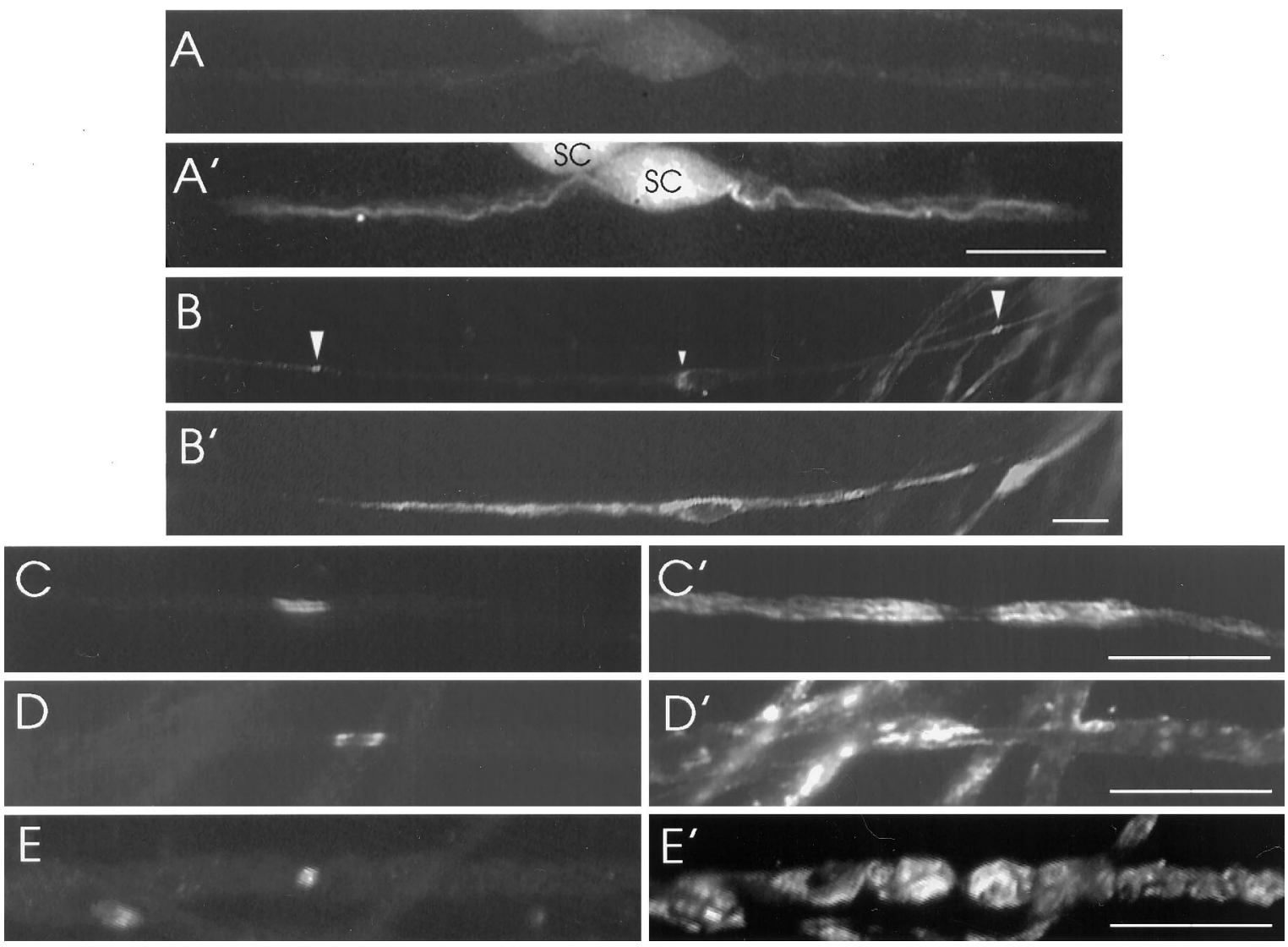

Figure 1. Variation of $\mathrm{Na}^{+}$channel aggregation by postnatal day. $A-E$ are labeled with the $\mathrm{Na}^{+}$channel antibody, $A^{\prime}$ is double-labeled with anti-S100, and $B^{\prime}-E^{\prime}$ are double-labeled with anti-MAG antibodies. $A, A^{\prime}$, An axon with an adherent Schwann cell, day P0. Na ${ }^{+}$channel aggregates are absent. The Schwann cell processes extend along the axon. $B, B^{\prime}$, Isolated Schwann cell with adjacent $\mathrm{Na}^{+}$channel aggregates (single process clusters, large arrowheads). Note labeling in region of Schwann cell body (small arrowhead), day P1. $C, C^{\prime}, \mathrm{Broad} \mathrm{Na}^{+}$channel cluster bordered by MAG ${ }^{+}$Schwann cell processes, day P3. $D, D^{\prime}, \mathrm{Na}^{+}$channel cluster with two foci (binary aggregate), day P4. $E, E^{\prime}$, Presumptive node of Ranvier with a focal cluster of $\mathrm{Na}^{+}$ channels, day P6. Scale bars, $25 \mu \mathrm{m}$.

discernible on the slide. On day $\mathrm{P} 0$, aggregation of sodium channels was limited to just one cluster per $5 \mathrm{~mm}$ (Fig. $3 A$, solid bars). By day P5 this frequency was maximal and was 36-fold higher than on day $\mathrm{P} 0$. The most rapid rate of cluster formation took place between days $\mathrm{P} 1$ and $\mathrm{P} 2$. Cluster frequency decreased beyond day P5.

It was instructive to examine the rate of appearance of the four different classes of $\mathrm{Na}^{+}$channel aggregates seen in these studies. These categories reached their maximal frequencies per unit length sequentially. Single process aggregates, associated with
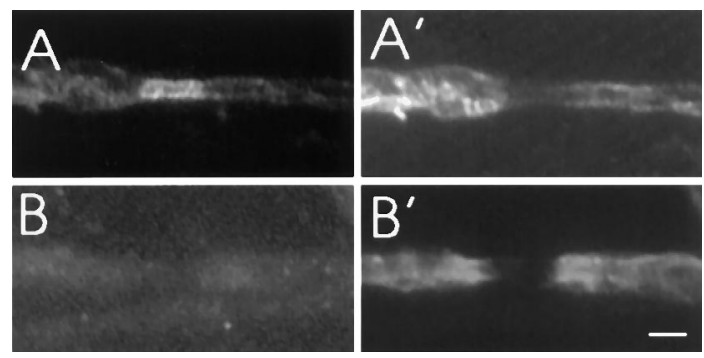

Figure 2. Control labeling with $\mathrm{Na}^{+}$channel antibody preabsorbed with the peptide antigen. $A$, Broad aggregate at day P3 labeled with normal (nonabsorbed) $\mathrm{Na}^{+}$channel antibody. $A^{\prime}$, Schwann cell processes doublelabeled with MAG antibody. $B$, Similar wide site labeled with preabsorbed $\mathrm{Na}^{+}$channel antibody. $B^{\prime}$, Processes are again $\mathrm{MAG}^{+}$. Scale bar, $10 \mu \mathrm{m}$. isolated Schwann cells, reached their peak the earliest and declined in frequency rapidly after day P3 (Fig. 3B, solid bars). The appearance of binary clusters (gray bars) was delayed initially $1 \mathrm{~d}$ relative to that of single process sites, but by day P3 their frequency clearly exceeded that of the latter. This is consistent with the hypothesis mentioned above that the binary clusters are formed by the lateral movement and fusion of two single process aggregates (Dugandzija-Novakovic et al., 1995). The longitudinal occurrence of broad aggregates (white bars) was higher than that of the single process and binary classes even at early times, and by day P4 these broad clusters were four times more numerous than the others. The broad sites, in turn, were superseded by presumptive nodes (Fig. $3 A$, white bars) after day $\mathrm{P} 4$, perhaps suggesting a compaction of the channels as the Schwann cell terminal processes mature. Note that the frequency of presumptive nodes per unit length declined beyond day P7 (Fig. $3 A$ ). This latter result may be attributable to the rate of linear growth of axons exceeding the rate of formation of new nodes at this stage. Internodal lengths have been shown to increase proportionally to limb length (Schlaepfer and Myers, 1973).

The length of clusters of $\mathrm{Na}^{+}$channels within three of the above four classes was also measured and plotted as histograms over days P2-P4 (Fig. 4). Single process sites were not included, because the number with clearly definable edges was too small for meaningful comparison with other categories. The lengths of both 

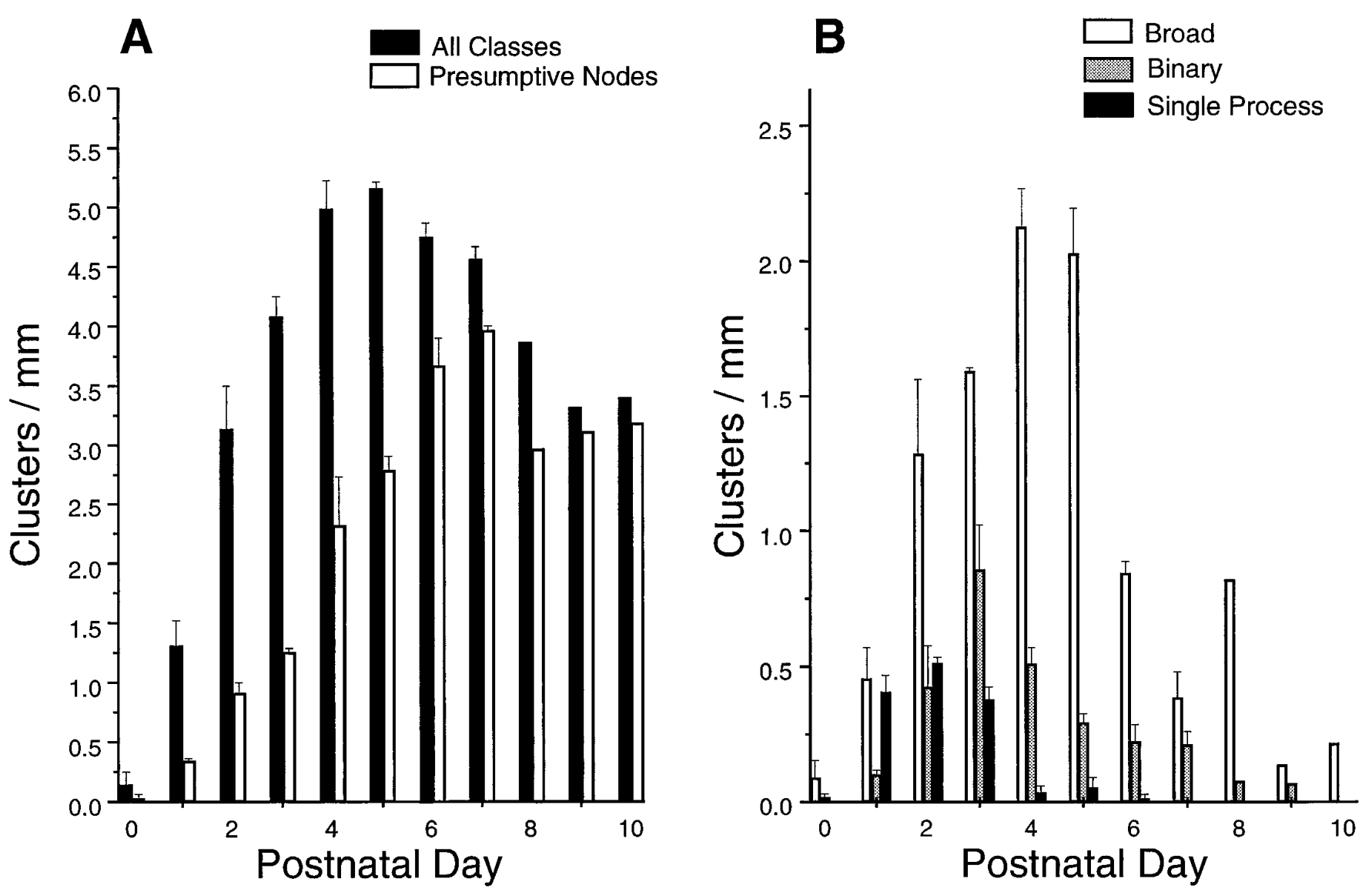

Figure 3. Histograms giving a quantitative analysis of the distribution of $\mathrm{Na}^{+}$channel aggregate classes per unit length of axon over days $\mathrm{P} 0-\mathrm{P} 10$. A, Solid bars, All aggregate types combined; white bars, presumptive nodes. $B$, White bars, Broad clusters; gray bars, binary clusters; solid bars, aggregates associated with isolated Schwann cells (single process clusters). Error bars, SEM.

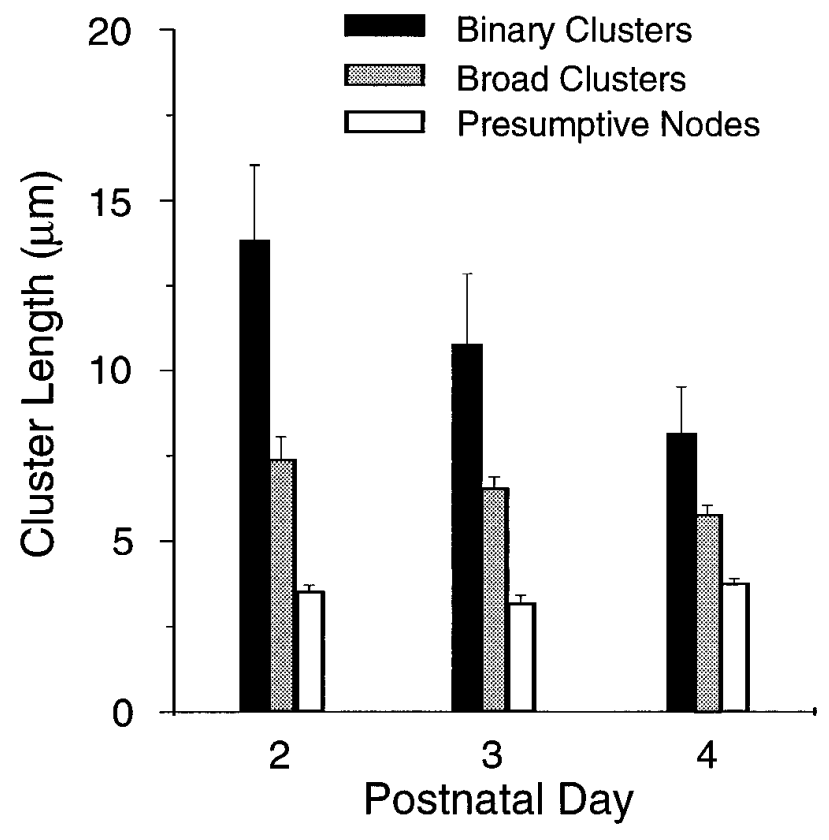

Figure 4. Histograms giving a quantitative analysis of the length of $\mathrm{Na}^{+}$ channel clusters from days P2-P4. Solid bars, Binary clusters; gray bars, broad clusters; white bars, presumptive nodes. Error bars, SEM. binary and broad sites decreased over this time frame, whereas the presumptive nodal length remained constant. Further, the average length of binary aggregates was significantly longer than that of broad clusters. Thus, these data support the idea that binary clusters coalesce into broad clusters and also that broad aggregates condense into nodes.

There is some evidence that peripheral nerve development occurs in a proximo-distal gradient, because Schwann cells are more numerous in proximal regions during early embryonic periods (Carpenter and Hollyday, 1992). Additionally, our preliminary results from thin-section ultrastructure suggest that myelination follows the same gradient. It is for this reason that the above studies all were done at the same level, just below the tibialperoneal split. However, over short distances, e.g., $<500 \mu \mathrm{m}$, there was relatively homogeneous development along a given axon, with aggregates within this region falling primarily within a single class. This was particularly noticeable on day P0 when axons either lacked clusters entirely or had several aggregates over the observed length. Additionally, Schwann cell bodies and $\mathrm{Na}^{+}$channel clusters often were aligned within a small group of neighboring axons. Figure 5 illustrates one such zone at day P4. The Schwann cells are denoted by asterisks. Groups of $\mathrm{Na}^{+}$channel clusters are seen at the left and right extremities of the figure. The distance between these groups was $400 \mu \mathrm{m}$. 


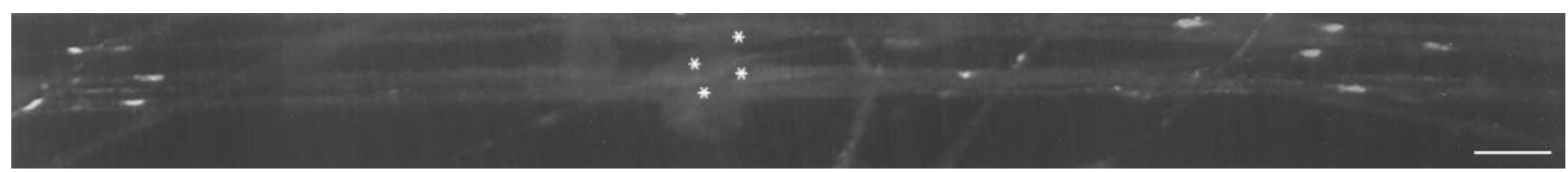

Figure 5. Alignment of $\mathrm{Na}^{+}$channel clusters at the ends of internodes of a group of neighboring parallel axons at day P4. The asterisks denote Schwann cell bodies. $\mathrm{Na}^{+}$channel clusters are near the left and right borders of the figure. The figure is a composite of four images. Scale bar, $25 \mu \mathrm{m}$.

\section{Relationship between sodium channel clustering and MAG expression by Schwann cells}

During development of the peripheral nervous system there is differential expression of several surface molecules. For example, L1 and neural cell adhesion molecule (NCAM) are present at early stages of Schwann cell-axon interaction. After formation of a 1:1 association and overlapping ensheathment, L1 and NCAM are down-regulated and MAG expression is increased markedly (Martini and Schachner, 1986). Thus, the appearance of MAG defines a particular state of differentiation of Schwann cells during myelination. There is a strong correlation between the expression of MAG in adherent Schwann cells and the formation of axonal aggregates of $\mathrm{Na}^{+}$channels. Associated Schwann cells initially were MAG-negative. On day P0 the majority of Schwann cells extended along axons lacked expression, and only a small fraction of cells was MAG-positive. A key observation concerns a correlation of $\mathrm{Na}^{+}$channel clustering with MAG expression at all days during the first postnatal week. $\mathrm{Na}^{+}$channel clusters were present only on axons associated with MAG-positive Schwann cells. Channel aggregates were never seen within a segment of axon lacking these cells. This was demonstrable as early as day P1, when the number of clusters first became appreciable. Figure $6 \mathrm{~A}$ contains two identifiable $\mathrm{Na}^{+}$channel aggregates (arrows) that are present along axons wrapped by MAG-positive Schwann cells, the fine processes of which extend to the cluster (Fig. $6 A^{\prime}$, arrows). At this stage, most axon-associated Schwann cells remain MAG-negative. Further, there seems to be a delay between the expression of MAG and the clustering of channels. Other fibers in the field also contain MAG-positive cells (Fig. $6 A^{\prime}$ ) but are not associated with detectable $\mathrm{Na}^{+}$channel clusters. In one experiment at day P0, only $5 \%$ of the MAG-positive cells bordered $\mathrm{Na}^{+}$channel clusters. Individual axons may contain strings of MAG-labeled Schwann cells and have no detectable $\mathrm{Na}^{+}$channel aggregates. By day $\mathrm{P} 4$ most of the Schwann cells adherent 1:1 with axons are expressing MAG (Fig. $6 B^{\prime}$ ) and have adjacent axonal $\mathrm{Na}^{+}$channel clusters (Fig. 6B). Arrows point to one such cluster in Figure $6 B$ and its corresponding location in Figure $6 B^{\prime}$.

Under circumstances in which neighboring Schwann cells are expressing significantly different levels of MAG, a $\mathrm{Na}^{+}$channel aggregate with graded density usually is observed in the interven-
Figure 6. Correlation between $\mathrm{Na}^{+}$channel aggregation and MAG expression. $A-C$, Labeling with $\mathrm{Na}^{+}$channel antibody. $A^{\prime}-C^{\prime}$, Double labeling with anti-MAG serum. $A$, $A^{\prime}$, Region from day P1 nerve. There are only two identifiable $\mathrm{Na}^{+}$channel clusters. These aggregates are each between $\mathrm{MAG}^{+}$Schwann cells. Arrows point to clusters $(A)$ and their corresponding locations $\left(A^{\prime}\right)$. $B, B^{\prime}$, Region from day P4 nerve containing a large number of $\mathrm{Na}^{+}$channel clusters bordered by $\mathrm{MAG}^{+}$Schwann cell processes. Arrows indicate one such cluster $(B)$ and its corresponding location $\left(B^{\prime}\right) . C, C^{\prime}$, A long $\mathrm{Na}^{+}$channel cluster with a density that tapers from right to left, day P3. The Schwann cell process on the right is intensely $\mathrm{MAG}^{+}$, whereas that on the left is labeled only weakly. Arrowheads denote the approximate boundary of the channel cluster. Scale bars, $25 \mu \mathrm{m}$.
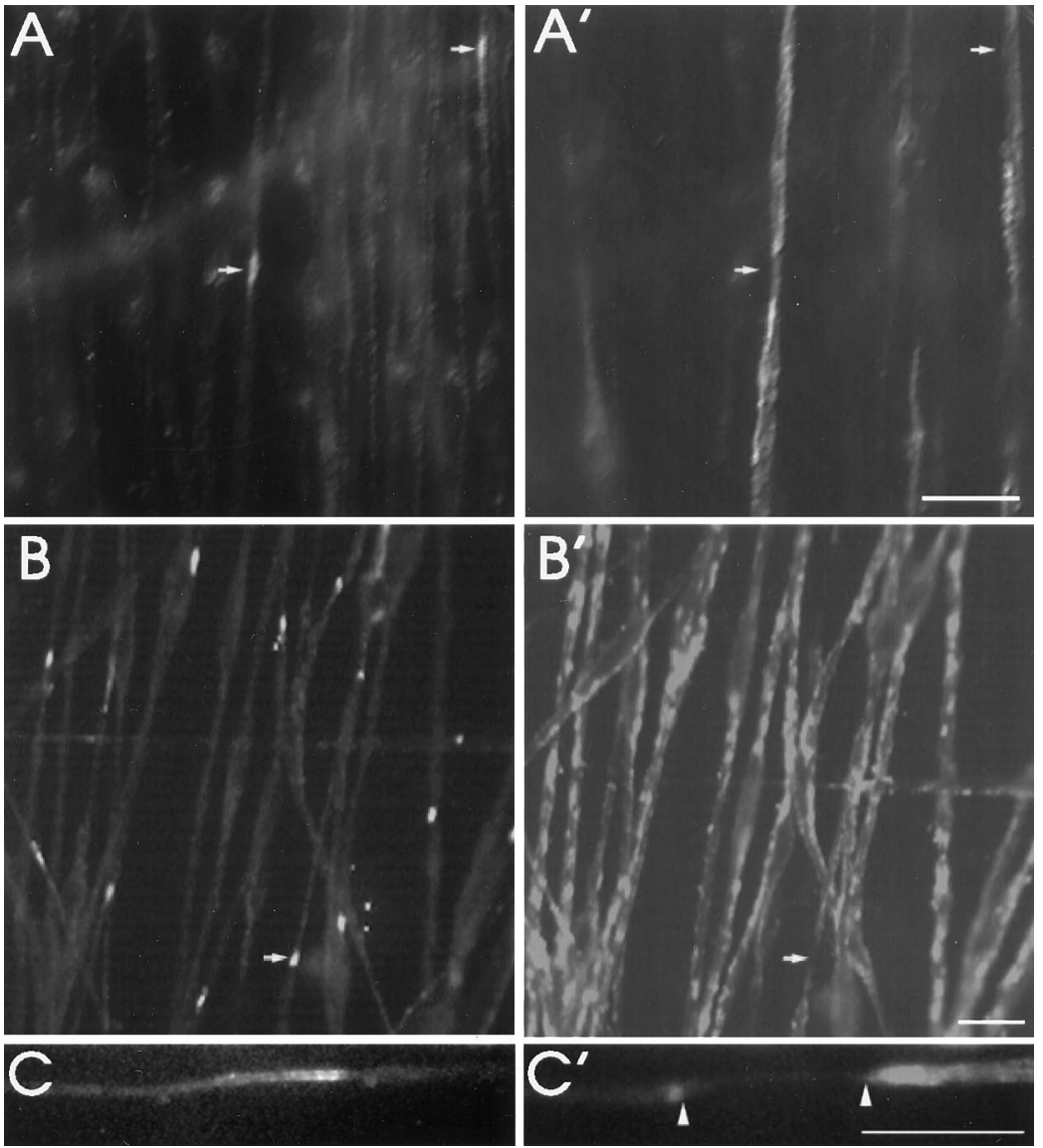

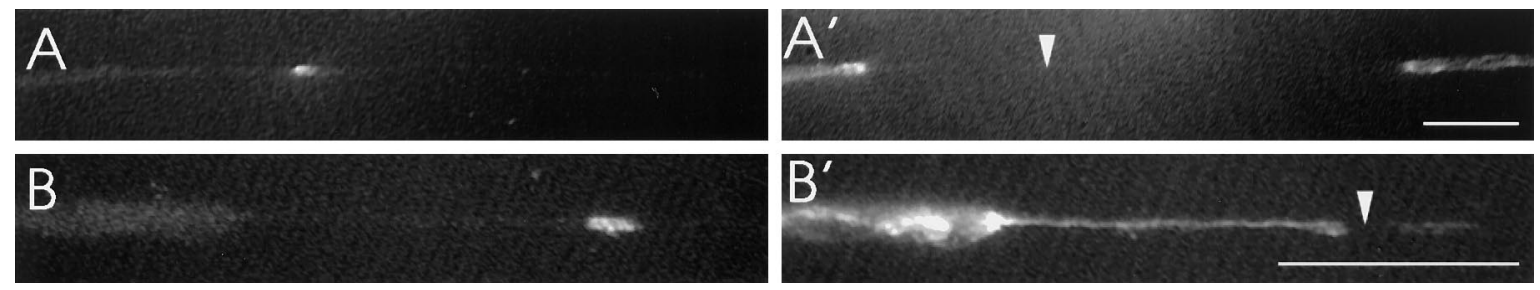

Figure 7. Testing for gaps between $\mathrm{Na}^{+}$channel clusters and Schwann cell processes. $A, B$, Labeling with $\mathrm{Na}^{+}$channel antibody. $A^{\prime}, B^{\prime}$, Double labeling with anti-MAG serum. $A, A^{\prime}$, An isolated axonal $\mathrm{Na}^{+}$channel aggregate not closely associated with Schwann cell processes. The arrowhead denotes the location of the channel cluster. $B, B^{\prime}$, An abrupt change in Schwann cell wrapping, resulting in a fine process extending to an $\mathrm{Na}^{+}$channel aggregate. Scale bars, $25 \mu \mathrm{m}$.

ing axonal space, as seen in Figure $6 C$. The sodium channel label is most intense next to the Schwann cell process with the greater level of MAG expression. This would correspond to the Schwann cell on the right in Figure $6 C^{\prime}$. Arrowheads denote the tips of MAG-labeled Schwann cell processes (Fig. $6 C^{\prime}$ ) and also mark the approximate extent of the $\mathrm{Na}^{+}$channel cluster.

The distribution of MAG within Schwann cells changed over the first postnatal week. During the earliest period, P1 through P3, MAG was widespread throughout the Schwann cell. This can be seen on day $\mathrm{P} 1$ in Figures $1 B^{\prime}$ and $6 A^{\prime}$ and on day $\mathrm{P} 3$ in Figure $1 C^{\prime}$. Between days $\mathrm{P} 4$ and P5 MAG label seems patchy, as seen in Figures $1 D^{\prime}$ and $6 B^{\prime}$. By day P6 MAG antiserum intensely labels regions that, presumably, are paranodes (Fig. $1 E^{\prime}$ ) and also forms bands of label in internodal regions (data not shown) that may be Schmidt-Lanterman incisures. In rare instances at this time a spherical Schwann cell was seen to bridge the gap between two closely spaced $\mathrm{Na}^{+}$channel clusters (data not shown). These cells were never positive for MAG but were brightly labeled with anti-S100. Similar Schwann cell bodies have been described during recovery from experimental allergic encephalomyelitis (Bonnaud-Toulze and Raine, 1980).

On rare occasions it seemed as if a clear gap were present between a cluster and any bordering Schwann cell processes. In Figure $7 A$ one such isolated $\mathrm{Na}^{+}$channel aggregate can be seen. The preparation was labeled for MAG in Figure $7 A^{\prime}$ to allow visualization of the extent of the Schwann cell processes. The arrowhead denotes the location of the $\mathrm{Na}^{+}$channel cluster. The closer process (on the left) is $45 \mu \mathrm{m}$ from the cluster. However, in most instances, a fine Schwann cell process could be seen to extend from bordering Schwann cells to an aggregate. Figure $7 B, B^{\prime}$ illustrates one such situation. The $\mathrm{Na}^{+}$channel aggregate appeared in Figure $7 B$ to be isolated, but when MAG was labeled (Fig. $7 B^{\prime}$ ), a fine process could be seen extending to it. It was considered possible that isolated aggregates were the result of Schwann cell process retraction or degeneration because of mechanical stress during the spreading procedure. As a control, nerves from days P1, P2, and P7 were fixed before desheathing and collagenase treatment, a P5 animal was perfusion-fixed, and the nerve was cryosectioned. Relatively few $\mathrm{Na}^{+}$channel clusters could be examined because of difficulties in spreading fixed fibers. All of these were bordered tightly by $\mathrm{MAG}^{+}$Schwann cell processes, without long gaps. Further, the classes of $\mathrm{Na}^{+}$channel structure were similar in these axons and included binary, broad, and presumptive nodal sites. Recently, we have found that the ultrastructural localization of $\mathrm{Na}^{+}$channel clusters relative to Schwann cell processes in remyelinating axons is independent of previous fixation (Novakovic et al., 1996).

\section{Block of Schwann cell proliferation}

The antimitotic agent mitomycin $\mathrm{C}$ was used to deplete the population of Schwann cells in a limited region of developing sciatic nerve. The drug was injected intraneurally on day $\mathrm{P} 0$, and the nerve was studied on day P6 or P7. Figure $8 A$ shows that there was a marked decrease in axonal ensheathment in the injection site and a corresponding dramatic loss of $\mathrm{Na}^{+}$channel aggregation as compared with uninjected animals. Those few axons that were associated with a Schwann cell $(S C)$ usually had $\mathrm{Na}^{+}$channel aggregates, although none are visible in this figure. As a control, we examined a region distal to the injection site. If the drug or injection procedure induced axonal damage, degeneration would be expected at this control site. As seen in Figure $8 B$, the nerve appeared normal at this location. There was significant Schwann cell ensheathment, and many presumptive nodes (arrow) were visible in axons. To test whether the effects of the injection were attributable to mechanical damage by the injection pipette rather than to the drug, an intraneural injection of vehicle alone was performed. In this case, the injection site generally appeared normal (Fig. 8C), but a few sections of the preparation were underdeveloped, containing Schwann cell-free segments of axons (data not shown).

\section{DISCUSSION}

Our results demonstrate a clear link between the degree of Schwann cell association and $\mathrm{Na}^{+}$channel clustering during development. Do Schwann cells induce clustering, or does $\mathrm{Na}^{+}$ channel aggregation occur de novo and, in turn, signal Schwann cells to form adjacent paranodal structures? Although it cannot be ruled out unequivocally, several lines of evidence render the latter mechanism unlikely. Firstly, it was very rare to see a $\mathrm{Na}^{+}$channel cluster isolated from Schwann cells. The few such instances that were observed have been discussed with respect to Figure 7. It was difficult to eliminate the possibility that a fine Schwann cell process was, in fact, present or had retracted during tissue preparation. Although occasional isolated clusters may exist, their low frequency would seem to preclude their representing a major route to node formation. Further, we never saw more than two clusters between the tips of neighboring Schwann cell processes. This should occur with a significant probability if $\mathrm{Na}^{+}$channel aggregation preceded glial adherence. Finally, local depletion of Schwann cells by the antimitotic drug mitomycin virtually eliminated $\mathrm{Na}^{+}$channel aggregation. This compound is not likely to act by disruption of axonal elements, e.g., cytoskeleton, because a distal region was normal. Disruption of Schwann cells by diphtheria toxin in a transgenic mouse (Messing et al., 1992) also prevented $\mathrm{Na}^{+}$channel clustering (Vabnick et al., 1996). 


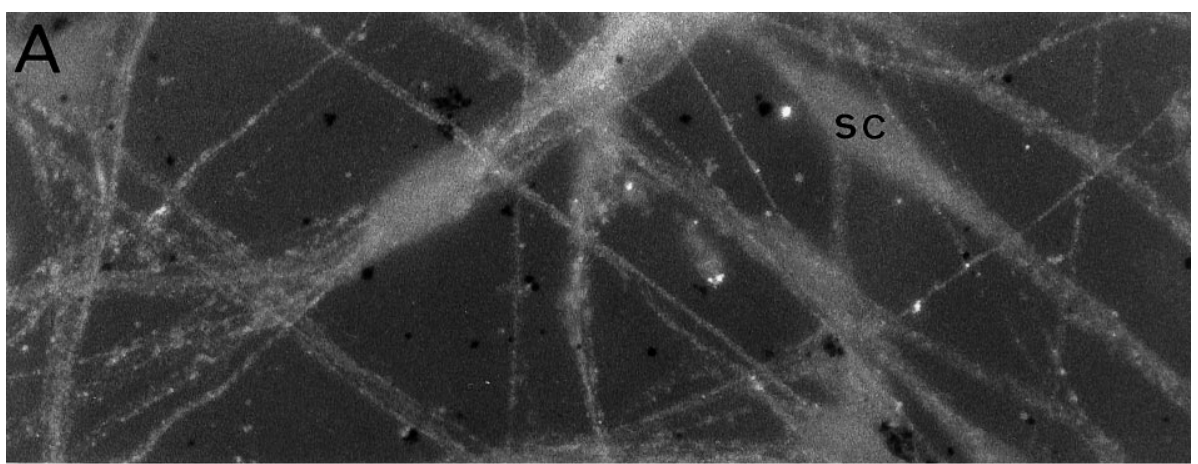

Figure 8. Block of Schwann cell proliferation in developing nerve focally injected on day $\mathrm{P} 0$ with mitomycin C. $A$, The injected zone on day $\mathrm{P} 7$ labeled for $\mathrm{Na}^{+}$channels. Many thin axons are seen, with few Schwann cells $(S C)$ and almost no identifiable $\mathrm{Na}^{+}$channel clusters. $B$, A region on the same nerve, distal to the injection site. Axons are covered by Schwann cells/myelin, and many $\mathrm{Na}^{+}$channel clusters are seen (arrow). C, Axons from a control animal injected on day P0 with Locke's and carmine red, examined on day P6. Many presumptive nodes with $\mathrm{Na}^{+}$channel clusters are seen. Scale bar, $10 \mu \mathrm{m}$.
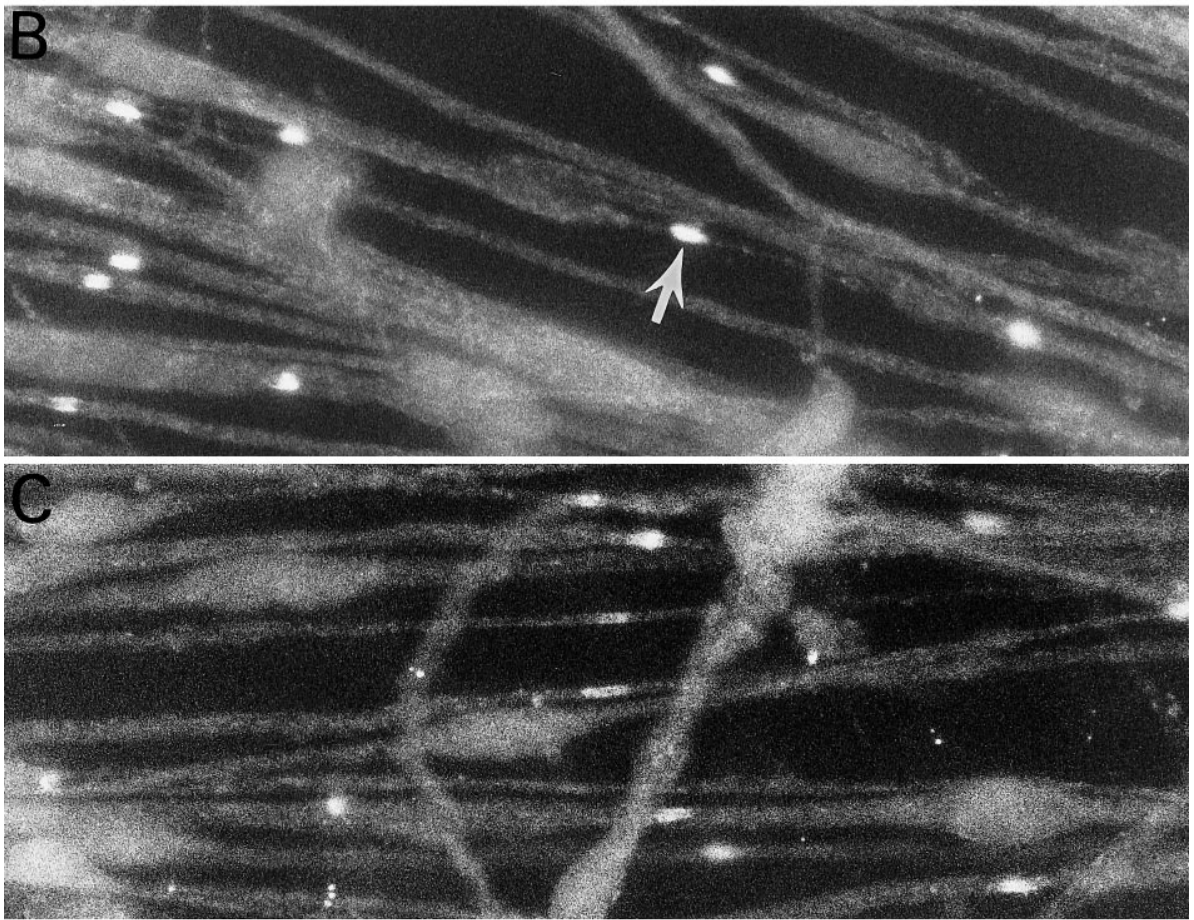

What can we determine regarding the sequence of events in node formation? Because broad nodes predominate, $\mathrm{Na}^{+}$channel aggregation must occur most often after two Schwann cell processes have approached each other closely. Other structures, although seen less frequently, provide essential information. Observations of single process clusters suggest that aggregation takes place near the tips of Schwann cell processes. Binary clusters were delayed $1 \mathrm{~d}$ relative to single process clusters and therefore may result from two of the latter moving closer together as Schwann cells grow along the axon. The continuous decrease in length of binary clusters and the fact that their average length is, at all times, longer than that of broad clusters suggest that some broad clusters form via fusion of binary pairs. Broad clusters, in turn, also became progressively shorter, presumably coalescing into presumptive nodes. Thus, we suggest that, whereas the precise route may vary somewhat, nodes of Ranvier form as $\mathrm{Na}^{+}$channels are induced to cluster by adherent Schwann cells.

Why do broad clusters predominate? It may be that the $\mathrm{Na}^{+}$ channel density in early premyelinated axons is very low, and immunocytochemical detection of an aggregate most often occurs only after two Schwann cell processes are in sufficient proximity to contribute simultaneously. In the compound action potential re- corded at $37^{\circ} \mathrm{C}$ from a day $\mathrm{P} 0$ nerve, three components could be resolved, with conduction velocities ranging from 0.3 to $1.0 \mathrm{~m} / \mathrm{sec}$. In premyelinated optic nerve, Waxman and coworkers (1989) have shown that the conduction velocity is $0.2 \mathrm{~m} / \mathrm{sec}$, and the corresponding density of $\mathrm{Na}^{+}$channels is $2 / \mu \mathrm{m}^{2}$. The density of $\mathrm{Na}^{+}$channels in our day $\mathrm{P} 0$ axons is, thus, likely to be substantially below the minimum for detection by immunofluorescence, which we estimate to be $\sim 50$ channels $/ \mu \mathrm{m}^{2}$. Even at day P0 some fibers could be found with a series of closely neighboring Schwann cells separated by short gaps suggestive of presumptive nodes. Almost none of these breaks, however, were populated with detectable $\mathrm{Na}^{+}$channel clusters. Just $2 \mathrm{~d}$ later large numbers of broad clusters were seen. Additionally, because newborn nerves are short and Schwann cell numbers grow rapidly, it may be that, in most cases, by the time these cells have adhered, extended processes and have begun ensheathment, the gap between them is already $<10 \mu \mathrm{m}$. Alternatively, a very different mechanism may be involved in which neuronal synthesis, axonal transport, and insertion of $\mathrm{Na}^{+}$channels are directed by an unknown signal primarily to these early nodal gaps. This would be a continuous, as opposed to a sequential, system.

The idea that Schwann cell processes induce aggregation of 
existing axolemmal $\mathrm{Na}^{+}$channels is supported by experiments on remyelinating nerve. Dugandzija-Novakovic et al. (1995) demyelinated sciatic nerves with lysolecithin in vivo and allowed them to recover. As proliferating Schwann cells adhered to demyelinated segments and extended processes, $\mathrm{Na}^{+}$channel clusters formed at their edges. When these glial processes grew longitudinally, the channel aggregates seemed to move with them, remaining always at their edges. Clusters associated with neighboring Schwann cells then seemed to fuse, forming binary structures similar to those seen here. Broad clusters were seen but were interpreted to represent a later stage, after fusion. In remyelination, as in development, block of Schwann cell proliferation with mitomycin prevented channel aggregation. Thus, the basic mechanism for $\mathrm{Na}^{+}$ channel clustering seems to be similar in both developing and remyelinating axons.

Our results are supported by previous studies on nodal differentiation that identified $\mathrm{Na}^{+}$channels by less specific morphological criteria. Wiley-Livingston and Ellisman (1980) studied freezefracture replicas of spinal roots over the same time period examined here. They found evidence for patches of 7.5-15 nm particles in the axolemma after day P0. These patches were usually adjacent to Schwann cells that had ensheathed the axon with only a few wraps and without evidence for compact myelin. The freeze-fracture particles seen in these studies are believed to represent $\mathrm{Na}^{+}$channels. Tao-Cheng and Rosenbluth (1983) also found clusters of large axolemmal E-face particles in freezefracture replicas of developing rat sciatic nerve. Some of these structures were observed to contain two regions of high particle density and were therefore similar to what we term a binary aggregate. At node-like specializations, longitudinal thin sections showed subaxolemmal undercoatings extending for $0.5-3 \mu \mathrm{m}$, a length corresponding to the most focal $\mathrm{Na}^{+}$channel clusters presented here. Thus, both the timing and organization of these particle clusters correspond closely with our immunofluorescence localization of $\mathrm{Na}^{+}$channels. More recently, Lambert et al. (1995), using immunocytochemistry, found clustering of ankyrin and $\mathrm{Na}^{+}$channels at the ends of Schwann cell/myelin processes in developing axons.

We noted earlier that, whereas gaps between $\mathrm{Na}^{+}$channel clusters and Schwann cell processes were rare and might result from tissue manipulation, they could not be ruled out entirely. Tao-Cheng and Rosenbluth (1983) found particle patches and specializations of the subadjacent cytoplasm exclusively in regions bordering Schwann cell processes. On the other hand, WileyLivingston and Ellisman (1980) noted infrequent instances of axonal particle patches that seemed to be isolated and not in close association with a Schwann cell. Furthermore, Waxman and Foster (1980) found small gaps between ferric ion-ferrocyanidestained regions and mature paranodal junctions in day P3 rat spinal roots. This procedure stains zones known to contain high $\mathrm{Na}^{+}$channel concentrations. Thus, whereas in the great majority of cases $\mathrm{Na}^{+}$channel aggregation occurs in close proximity to Schwann cell processes, the possibility of clustering at significant distances in rare cases remains.

Schwann cell differentiation is marked by a transition in the expression of adhesion molecules (Martini and Schachner, 1986). Of particular importance here, MAG expression is delayed until Schwann cells have reached a 1:1 relation with axons and are at an early stage of ensheathment ( $\sim 1.5$ wraps) (Martini and Schachner, 1986). Martini and Schachner (1986) also found that the distribution of MAG within mouse Schwann cells was not static during postnatal development. By the time of myelin com- paction, MAG was restricted to paranodal loops, periaxonal regions, mesaxons, and Schmidt-Lanterman incisures. We found that $\mathrm{Na}^{+}$channel clustering took place only after up-regulation of MAG expression but before its redistribution. Further, at days P0 and P1 there is a delay between the expression of MAG and $\mathrm{Na}^{+}$ channel clustering. This may be attributable to the possibility noted above that the $\mathrm{Na}^{+}$channel density at this time is below the minimum required for immunofluorescence detection. Alternatively, a Schwann cell signal for axonal channel clustering may be distinct from MAG but develop only after MAG expression. MAG-deficient knock-out mice have only minimal structural abnormalities until $\sim 8$ months of age, when they show both axonal and myelin degeneration (Li et al., 1994; Montag et al., 1994; Fruttiger et al., 1995). We have found that node formation in MAG $-/-$ mice is delayed at most $1 \mathrm{~d}$ when compared with $\mathrm{MAG}^{+/+}$controls (our unpublished data). Thus, MAG itself is not likely to represent an essential signal, but its correlation with $\mathrm{Na}^{+}$channel clustering suggests that Schwann cells must reach this particular developmental state to be effective.

The glial-neuronal interaction involved in myelination during development is highly complex. We have demonstrated here an additional component to this process by showing that Schwann cells influence the clustering of $\mathrm{Na}^{+}$channels in the axolemma that is essential for node of Ranvier formation. At birth, $\mathrm{Na}^{+}$ channel aggregates and presumptive nodes in rat sciatic fibers are virtually absent. By the end of the first postnatal week, almost all axons have a full complement of new nodes of Ranvier with highly focal $\mathrm{Na}^{+}$channel clusters. We have defined the developmental stage at which Schwann cells induce channel aggregation, although the molecular signals that are responsible remain unknown.

\section{REFERENCES}

Bonnaud-Toulze EN, Raine CS (1980) Remodelling during remyelination in the peripheral nervous system. Neuropathol Appl Neurobiol 6:279-290.

Carpenter EM, Hollyday M (1992) The location and distribution of neural crest-derived Schwann cells in developing peripheral nerves in the chick forelimb. Dev Biol 150:144-159.

Chiu SY (1993) Differential expression of sodium channels in acutely isolated myelinating and non-myelinating Schwann cells of rabbits. J Physiol (Lond) 470:485-499.

Chiu SY, Shrager P, Ritchie JM (1984) Neuronal-type $\mathrm{Na}^{+}$and $\mathrm{K}^{+}$ channels in rabbit cultured Schwann cells. Nature 311:156-157.

Dugandzija-Novakovic S, Koszowski AG, Levinson SR, Shrager P (1995) Clustering of $\mathrm{Na}$ channels and node of Ranvier formation in remyelinating axons. J Neurosci 15:492-502.

Fruttiger M, Montag D, Schachner M, Martini R (1995) Crucial role for the myelin-associated glycoprotein in the maintenance of axon-myelin integrity. Eur J Neurosci 7:511-515.

Howe JR, Ritchie JM (1990) Sodium currents in Schwann cells from myelinated and non-myelinated nerves of neonatal and adult rabbits. J Physiol (Lond) 425:169-210.

Joe EH, Angelides K (1992) Clustering of voltage-dependent sodium channels on axons depends on Schwann cell contact. Nature 356:333-335.

Lambert S, Michaely P, Davis JQ, Bennett V (1995) Ankyrin clustering in the coordinate recruitment of ion channels and adhesion molecules during morphogenesis of the node of Ranvier. Mol Biol Cell [Suppl] 6S:98a.

Li C, Tropak MB, Gerlai R, Clapoff S, Abramow-Newerly W, Trapp B, Peterson A, Roder J (1994) Myelination in the absence of myelinassociated glycoprotein. Nature 369:747-750.

Martini R, Schachner M (1986) Immunoelectron microscopic localization of neural cell adhesion molecules (L1, N-CAM, and MAG) and their shared carbohydrate epitope and myelin basic protein in developing sciatic nerve. J Cell Biol 103:2439-2448.

Messing A, Behringer RR, Hammung JP, Palmiter RD, Brinster RL, Lemke G (1992) P0 promoter directs expression of reporter and toxin genes to Schwann cells of transgenic mice. Neuron 8:507-520. 
Montag D, Giese KP, Bartsch U, Martini R, Lang Y, Bluthmann H, Karthigasan J, Kirschner DA, Wintergerst ES, Nave KA, Zielasek J, Toyka KV, Lipp HP, Schachner M (1994) Mice deficient for the myelin-associated glycoprotein show subtle abnormalities in myelin. Neuron 13:229-246.

Nolte C, Schachner M, Martini R (1989) Immunocytochemical localization of the neural cell adhesion molecules L1, N-CAM, and J1 in Pacinian corpuscles of the mouse during development, in the adult, and during regeneration. J Neurocytol 18:795-808.

Novakovic SD, Deerinck TJ, Levinson SR, Shrager P, Ellisman MH (1996) Clusters of axonal $\mathrm{Na}^{+}$channels adjacent to remyelinating Schwann cells. J Neurocytol, in press.

Park CM, Clegg KE, Harvey-Clark CJ, Hollenberg MJ (1992) Improved techniques for successful neonatal rat surgery. Lab Anim Sci 42:508-513.

Poltorak M, Sadoul R, Keilhauer G, Landa C, Fahrig T, Schachner M (1987) Myelin-associated glycoprotein, a member of the L2/HNK-1 family of neural cell adhesion molecules, is involved in neuron-oligodendrocyte and oligodendrocyte-oligodendrocyte interaction. J Cell Biol 105:1893-1899.

Rieger F, Daniloff JK, Pincon-Raymond M, Crossin KL, Grumet M, Edelman GM (1986) Neuronal cell adhesion molecules and cytotactin are colocalized at the node of Ranvier. J Cell Biol 103:379-391.

Ritchie JM, Black JA, Waxman SG, Angelides KJ (1990) Sodium channels in the cytoplasm of Schwann cells. Proc Natl Acad Sci USA 87:9290-9294.

Schlaepfer WW, Myers FK (1973) Relationship of myelin internode elongation and growth in the rat sural nerve. J Comp Neurol $147: 255-266$.
Seilheimer B, Persohn E, Schachner M (1989) Antibodies to the L1 adhesion molecule inhibit Schwann cell ensheathment of neurons in vitro, part 1. J Cell Biol 109:3095-3103.

Shatz CJ (1990) Impulse activity and the patterning of connections during CNS development. Neuron 5:745-756.

Shrager P (1989) Sodium channels in single demyelinated mammalian axons. Brain Res 483:149-154.

Sontheimer H, Black JA, Ransom BR, Waxman SG (1992) Ion channels in spinal cord astrocytes in vitro. I. Transient expression of high levels of $\mathrm{Na}^{+}$and $\mathrm{K}^{+}$channels. J Neurophysiol 68:985-1000.

Tao-Cheng JH, Rosenbluth J (1983) Axolemmal differentiation in myelinated fibers of rat peripheral nerves. Brain Res 285:251-263.

Vabnick I, Novakovic SD, Levinson SR, Schachner M, Shrager P (1995) Schwann cells influence the organization of sodium channels during development. Soc Neurosci Abstr 21:322.

Vabnick I, Messing A, Chiu SY, Levinson SR, Schachner M, Shrager P (1996) Modified $\mathrm{Na}^{+}$channel distribution in developing and adult hypomyelinating transgenic mice. Soc Neurosci Abstr, in press.

Waxman SG, Foster RE (1980) Development of the axon membrane during differentiation of myelinated fibres in spinal nerve roots. Proc $\mathrm{R}$ Soc Lond [Biol] 209:441-446.

Waxman SG, Black JA, Kocsis JD, Ritchie JM (1989) Low density of sodium channels supports action-potential conduction in axons of neonatal rat optic nerve. Proc Natl Acad Sci USA 86:1406-1410.

Wiley-Livingston C, Ellisman MH (1980) Development of axonal membrane specializations defines nodes of Ranvier and precedes Schwann cell myelin elaboration. Dev Biol 79:334-355. 